\title{
Papers
}

Andrew Parsons,

a director in McKinsey \& Company's New York Office and leader of their worldwide marketing practice, has 23 years' experience in resolving strategy, organisation and operational problems for leading companies. Before joining McKinsey, he was vice president of marketing for the Prestige Division of American Home Products. He was also a principal in the setting up and subsequent sale to Xerox of Kurzweil Computer Products, a pioneer in artificial intelligence.
Keywords: Consumer expectations, marketing strategy, market research, value
Andrew Parsons,

Director,

McKinsey \& Company,

55 East 52nd Street,

21st Floor, New York,

New York 1002, USA

Tel: +1 2124467000

E-mail:

andrew.parsons@mckinsey.com

\section{Organising for the interactive marketing of tomorrow}

\author{
Andrew J. Parsons
}

Date received (in revised form): 3 June 1999

\begin{abstract}
The author argues that consumer expectations are being redefined, while technologies are enabling new marketing capabilities which meet and feed these expectations. In particular, consumers want more than functional benefits which seem increasingly undifferentiated. In addition to product quality and value, they are looking for process and relationship benefits which 'access' and 'interfacing' technologies are increasingly able to provide. Traditional businesses are being attacked by new competitors who use technology to meet consumer expectations with innovative value propositions.

Marketers need to respond by developing new strategies, refocusing their marketing investments and tactics and developing new organisational capabilities and processes. New strategies require redefining marketing processes from the traditional linear 'choose the value, deliver, communicate' approach to a faster, iterative approach which consists of multiple tailored value propositions. Meanwhile cost savings from a streamlined value delivery system will be reinvested in marketing spending targeted at micro-segments and increasingly in interactive media. These fundamental shifts in marketing strategy and tactics require companies to adopt a new mindset and build new skills, organisational structures, staff and systems.

Among the key skills are understanding value exchange with customers, integrating multiple data sources, predictive modelling and integrative leadership. The structure that facilitates these skills will be organised around cross-functional teams aligned around customer opportunities. Finally, the systems infrastructure requirements are substantial across the board from customer care systems to one-to-one Internet applications.

There are four stages in moving towards full interactive marketing. So far nobody has reached stage 4 . There are a number of critical decisions companies need to make now about how to move through the stages.

This paper is based on the author's presentation at the IDM Symposium 1999.
\end{abstract}

\section{Introduction}

Crystal-ball gazing can be risky, especially for experts. Alexander Graham Bell predicted that telephones would be largely used for transmitting 
Experts are rushing to their crystal balls almost as fast as the Internet start-ups are rushing to IPO

\author{
The new model \\ allows suppliers \\ to interact with \\ customers and \\ customers to \\ interact with one \\ another anywhere, \\ everywhere, and \\ anytime
}

\section{Why are consumers looking for more? It is because products seem to them to be increasingly undifferentiated}

symphonies to remote areas. Tom Watson, chairman of IBM, forecast that only five computers would be sold; even the young Bill Gates is recorded as prophesying that ' $640 \mathrm{~K}$ ought to be enough for anybody'.

Since interactive marketing is such a new and dynamic field, experts are rushing to their crystal balls almost as fast as Internet start-ups are rushing to intial public offerings. Given the history of errant predictions, perhaps we should be worried that most of the experts agree on at least one thing: Internet-based marketing is a growing force that is transforming most traditional ways of going to market. Where the experts differ is on the rate at which new technologies will be adopted or consumers will fundamentally change their behaviour. However, for today's under- $25 \mathrm{~s}$ the vision of the interactive future is unclouded by legacy systems or traditional channel relationships and they are unfazed by the myriad migration paths. This is a vision of a pervasive shift from a system of mass communication driving consumers to a real-world point of sale. The new model is one of personal communication that allows suppliers to interact with customers and customers to interact with each other anywhere, everywhere, and anytime.

This paper will examine the primary drivers of the new marketplace and then explore how marketing strategy, resource allocation and organisation capabilities and processes will need to change to respond to the opportunities (and threats) of these developments.

Three major trends are driving this emerging future propelled by changes in consumer expectations, emerging technologies and innovative new competitors. These trends are now examined.

\section{Redefined consumer expectations}

Consumer expectations are being redefined as more educated consumers have greater access to information about products and services, and increasingly want more than functional benefits such as product and performance attributes, value and quality. Why are consumers looking for more? It is because products seem to them to be increasingly undifferentiated. Take even automobiles, where quality, reliability and performance have always been key buying factors. In 1981 automobiles in the US market had between two and eight defects per vehicle at delivery, with a median between four and five. By 1995, the worst performer was roughly equal to the best of 1981 and the range between models was trivial. Similarly, performance as indicated by acceleration times has become much less differentiated. Consumers perceive this lack of differentiation, and most now agree that cars seem more and more alike in quality and features. With this lack of differentiation, consumers now want a convenient, pleasant process for getting information about the product or service and making a transaction.

In addition, customers are looking for relationship benefits - the sense of well-being and confidence generated by a history of consistently good experiences and personalised service. This type of relationship encourages consumers to share information about themselves for the value they receive in return; for example, recommendations of books or vacations that fit with their particular interests. Value-based exchange deepens consumer loyalty. 
Parsons

Figure 1: Consumers value process and relationship benefits as highly as functional benefits

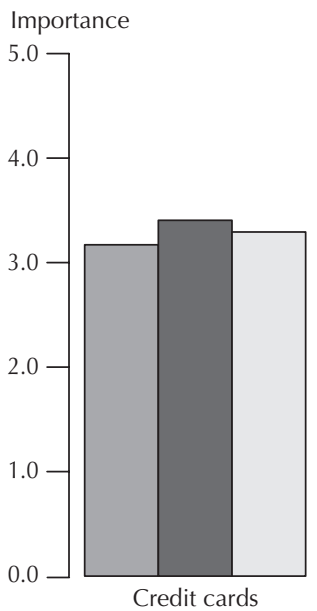

Source: McKinsey research
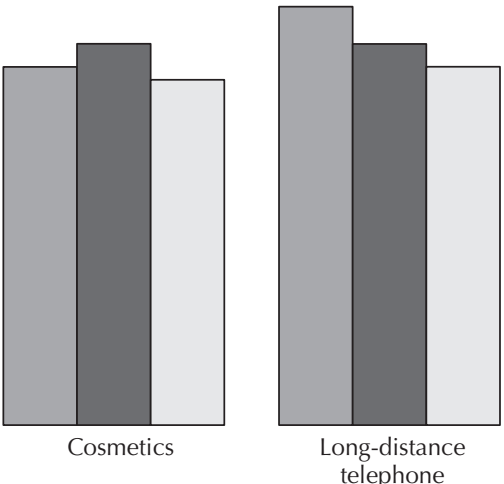

telephone
Functional benefits Process benefits Relationship benefits

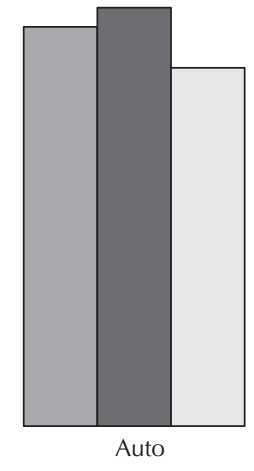

The traditional functional benefits are joined by process and relationship benefits

\author{
Data flows from \\ consumer \\ touchpoints like \\ call centres, mail, \\ Internet and stores \\ will be integrated \\ seamlessly
}

Now traditional functional benefits are joined by process and relationship benefits. Recent market research has quantified the importance that consumers attach to process and relationship benefits versus functional benefits (Figure 1). For example, for credit cards, cosmetics and automobiles, the way you buy and the consumer relationship experience are more important than functional benefits. Only in long-distance telephone does the consumer rate function above everything else. But even here process and relationship still rank high. While basic telephone technology may apparently not be taken for granted, information technology is rapidly enabling new capabilities that can serve marketers in improving functional and relationship benefits.

\section{Emerging technologies}

New technologies are providing multiple forms of access both in the devices, which receive and transmit, and in the pipe along which the data flow. The current bandwidth constraints of the twisted-pair telephone line are being loosened by new technology, and may be supplanted over time by cable and wireless. Certainly, AT\&T has recently placed a $\$ 100 \mathrm{bn}$ bet that in North America cable networks will be the channel of choice for digital datastreams, be they for video or voice.

At the same time, interfacing technologies are markedly upgrading the ability to target and personalise the interaction and provide network access to customer history so that data flows from multiple consumer touchpoints like call centres, mail, Internet and stores will be integrated seamlessly. These personalised interactions will in turn link to more product and service delivery customisation capabilities that will permit made-to-order manufacturing. In assembly-based industries like PCs and cars the consumer will have much greater ability to select how and when a product or service is delivered or indeed paid for. Digital gift certificates and cyber cash are just a few of the emerging technologies that are reshaping the way we think about payment in the virtual world, 
Technology is having a dramatic impact on the very concept of price, with dynamic pricing rapidly replacing price benchmarks

\section{If overused or intrusive, new technologies will create consumer attention burnout and relationships will decline}

while smart cards may capture digital information benefits in the physical world. Technology is also having a dramatic impact on the very concept of price, with dynamic pricing rapidly replacing price benchmarks. Companies can now adjust pricing by location, time of day, product availability and customer profile. Auctions are becoming a popular pricing method in both consumer and business niches of the Internet.

In sum, these technologies will greatly enhance marketers' capabilities to select and communicate to target customers and lower the cost to serve them, through more tailored value propositions, and achieve an instant intelligent interaction with them, as they think appropriate. The new technologies will allow a move from a marketing world of delays, bounds and person dependency. This world is slow, inflexible and simultaneously uniform in communication but variable in delivery with high marginal costs. The new environment will have immediate and continuous availability of access and service and be intelligent (that is, have a memory and be able to adapt offerings and address them to recognised individuals). Because it is network enabled it will be able to engage in many personalised interactions at low marginal cost and facilitate the linkage of parties. Despite this great power, however, it should be remembered that if the enhanced capability for interaction is overused or intrusive, the new technologies will create consumer attention burnout and relationships will decline.

If wisely used these technologies not only build greater customer loyalty/retention for increasing long-term customer value but will also stimulate short-term revenue gains. For example, personalised callcentre technology does grow sales. In the author's experience, providing these tools to agents typically increases catalogue orders by 5-12 per cent and can raise the cross-sell response rate by $40-50$ per cent.

\section{Innovative new competitors}

With all these new capabilities available, new competitors are emerging with innovative value propositions. Many of them are new industry entrants. As is typical in any technology or marketplace discontinuity, incumbents are slow to react as they resist leading the creative destruction of their existing profitable business. One can see how new attackers have developed innovative approaches across multiple industries. Clearly Amazon.com is revolutionising both the process and relationship benefits of book and music buying with its massive selection, powerful search engines and adaptive learning tools that can recommend books or CDs based on purchase history. Auto-by-Tel innovated in showing consumers their options by providing price comparisons, car reviews and customer feedback, and has started to reshape the entire automobile purchase process and cycle time. In the old world the average family researched models, picked two and shopped at four dealers with typically four visits to the dealer selected. In the new world of Auto-by-Tel and its competitors, the family researches models on the Internet, picks one, gets full information and then picks two dealers to shop at. The new process saves over half the 


\section{E-Schwab and other online brokers have established a brand position that traditional retail brokerages will struggle to overcome}

time and incidentally reduces dealer labour cost by 75 per cent. This saving will presumably lead to leaner dealer pricing.

Innovative outsiders created niche businesses that have rapidly entered the mainstream and redesigned business economic models. For example, the attractiveness of completing an online securities transaction with pricing and timing options and e-mail confirmation has developed a new customer segment that is rapidly growing and is expected to amount to account for 60 per cent of all US stock trades within five years. E-Schwab has established a brand position, alongside newcomers E*Trade, Waterhouse Securities and others, that the traditional retail brokerages will struggle to overcome. Similarly, automotive information online is expected to influence nearly half of all car sales within five years. By then direct-to-consumer deliverers like Peapod and Streamline may have 10 per cent of the slow moving grocery market (Figure 2).

In sum, consumer expectations are being redefined. Technology is enabling new capabilities and there are lots of new competitors.

How should marketers respond? They will need new strategies, different marketing resource deployment and a new approach to organisation, particularly marketing organisation.

Figure 2: Substantial volume will shift to new attacker models Percentage of total industry volume

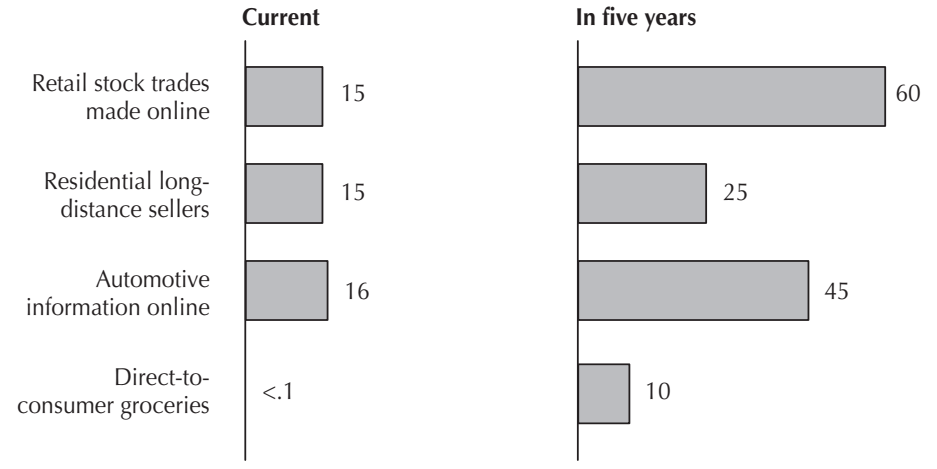

\section{Modify marketing strategy}

Strategy should drive the other responses. While maintaining some strategic flexibility can be critical in dealing with the uncertainties of external change, there are some basic elements to all winning new-age strategies: they succeed by redesigning or reconceiving both the value proposition and the value delivery system to generate superior economics. The better economics can come from increased revenues per customer and lower customer acquisition and service costs. Marketers achieve this by better targeting the mix of functional, process and relationship benefits and using information technology to remove from the system costs like expensive intermediaries in brokerage, insurance and even car dealerships.

Saturn is a good example of an industry insider reinventing strategy by changing the value proposition by several innovations: creating a no- 
Saturn has generated a distinctive appeal for a consumer segment who will camp out at the factory for festivities

The new marketing approach will be iterative, using a continuous 'try it, test, redefine it' delivery approach
Figure 3: Redefining traditional marketing processes

\begin{tabular}{|c|c|c|}
\hline $\begin{array}{l}\text { Choose the } \\
\text { value }\end{array}$ & $\begin{array}{l}\text { Deliver the } \\
\text { value }\end{array}$ & $\begin{array}{l}\text { Communicate } \\
\text { the value }\end{array}$ \\
\hline $\begin{array}{l}\text { Identify the key } \\
\text { benefits to provide } \\
\text { to target customers }\end{array}$ & $\begin{array}{l}\text { Deliver single value } \\
\text { proposition based on } \\
\text { functional benefits }\end{array}$ & $\begin{array}{l}\text { Communicate message } \\
\text { through mass, one-way } \\
\text { advertising }\end{array}$ \\
\hline
\end{tabular}

haggle sales process and trust in the dealer while streamlining the value delivery system by incorporating options as standard and reducing dealer inventory costs. The limited but dependable product line, noncommissioned salesforce, exclusive dealer territories and friendly, supportive buying environment have generated a distinctive appeal for a consumer segment who will camp out at the factory for festivities. As a result, Saturn sales are around double what they would have been with a traditional functional benefit-based strategy.

In particular, developing new marketing strategies requires a different thinking process about marketing. Traditionally marketers selected the mix of benefits to target customers, pushed the products through a singular go-to-market system and then pulled demand through mass advertising. This was a monumental and linear process (Figure 3).

The new marketing approach will be iterative, based on identifying benefit areas in function, process or relationship where there is room for redefining value and creating a continuous 'try it, test it, redefine it' delivery approach (Figure 4). Instead of one massive value proposition and delivery approach, the new marketing approach will use multiple tailored approaches for economically viable customer segments (Figure 5). If this sounds like integrating many principles of direct marketing into traditional mass marketing - it is. There is a major difference, however. New-age iterative marketing is strategically flexible as well as tactically agile - it will be based on behavioural/attitudinal and usage segmentation and lifetime customer value, not just response factors. Simultaneously, it will use technology to change real product and service benefit packages rapidly.

Figure 4: New marketing approach

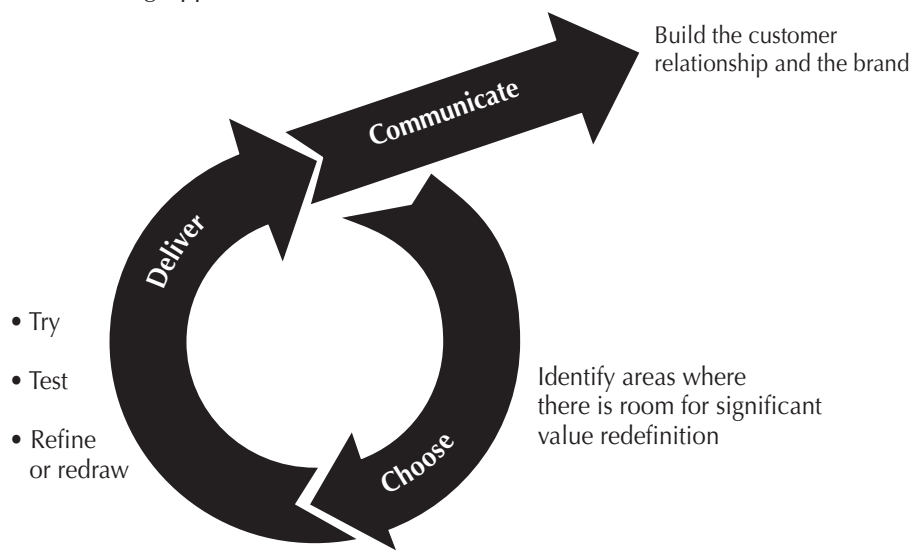


Already, a significant proportion of offline buyers conduct much of their pre-purchase research online
Figure 5: New marketing approach across segments

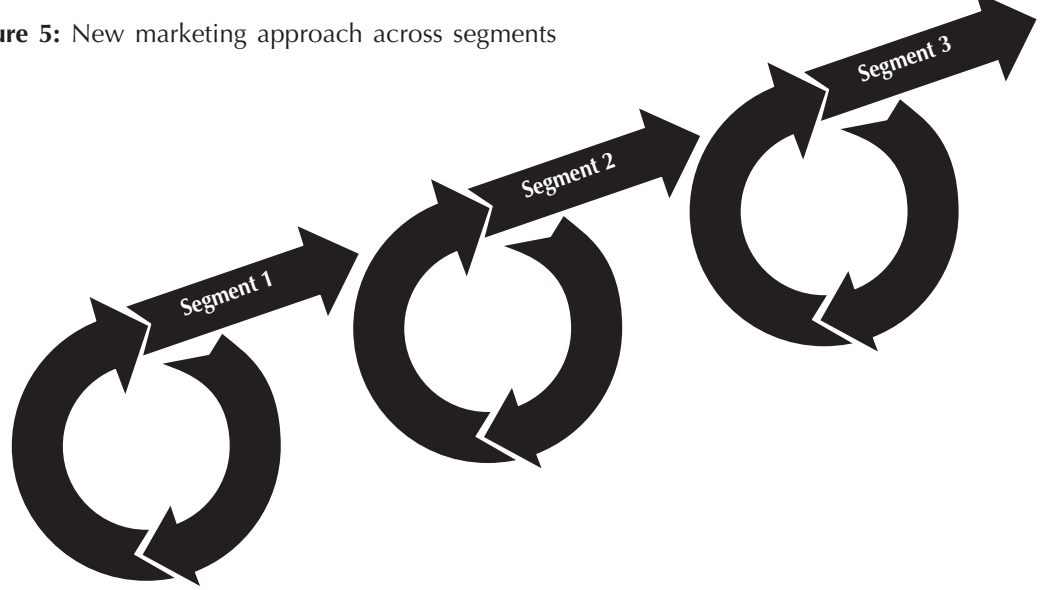

\section{Allocate marketing resources differently}

What are the implications of these new marketing strategies for marketing investment levels? Spending will increase, with cost savings from a streamlined delivery system partly captured by the consumer, partly reinvested in building the marketing technology infrastructure and partly reallocated to spending more targeted at specific higher lifetime value micro-segments. In addition, more investment of old physicalworld marketers will be directed towards establishing dialogues with customers which lead to better information about specific customer needs and more value delivered. Increasingly marketers will need to develop integrated online/offline spending plans as the means of acquiring customers. Indeed, already a significant proportion of offline buyers conduct much of their pre-purchase research online (Figure 6).

A new mix in marketing spend allocation will emerge, with shifts from mass media to much more targeted media and continuous relationship management programmes. In cosmetics, for example, a significant proportion of an increased spend is likely to be devoted to

Figure 6: Prepurchase research activity

Percentage of total industry volume
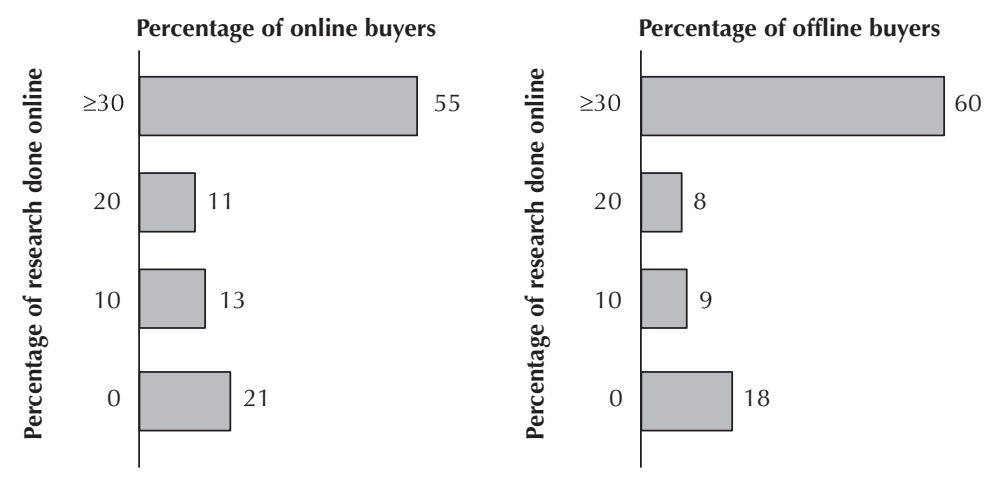

Source: BizRate survey 


\section{Consumers have the ultimate power to track self-behaviour, avoid identification and only release information when they are confident that value will be exchanged}

\section{Measurement of traditional media effectiveness appear increasingly superficial}

\section{Companies will need a very different mindset in which they parallel manage a portfolio of initiatives}

customer dialogue through websites, kiosks and call centres, and much less budgeted to mass sampling. Total media spending is likely to hold its share but there will be a marked increase in addressable vehicles. Most of the growth will come in Internet spending, possibly at the expense of direct mail. At the same time we can expect major Web players to draw traffic to their sites by advertising in traditional media.

Increased investment in customer dialogue will be based on value exchange, with the consumers providing information about themselves in return for specific value from the marketer in the form of, for example, recipe suggestions, healthcare advice or tailored promotional offerings. The recent development of reverse cookies has allowed the consumer ultimate power to track self-behaviour, avoid identification and only release information when they are confident that value will be exchanged.

More demanding metrics will measure marketing spend effectiveness, based on the ability to capture information in real time. Current measures will be considered inadequate. On the revenue side, market share and retention rates will be replaced by share of customer segment. Cost to acquire will shift from response rates to marketing ROI. Cost to serve will move to take rates on available process options. Profitability will be measured by lifetime customer value.

Precise measures of exposure, response and action on the Internet will make measurement of traditional media effectiveness appear increasingly superficial. As a result, marketers will be pressing harder on the broadcast and cable networks and print media for more precise and actionable metrics.

\section{Create new organisational designs}

How should companies organise to compete effectively in this emerging world of new marketing strategies, tactics and interaction? Firstly, they will need a very different mindset in which they parallel manage a portfolio of initiatives that are read fast and reiterated based on marketplace learning. Flexibility and diversity will be key, but so will the ability to integrate data instantly from multiple consumer touchpoints. This will require a range of new skills and a new decisionmaking structure with new staff supported by a greatly expanded systems infrastructure.

Marketing skills will move from snapshot data (for example, annual tracking studies) to integrated data from multiple sources and building predictive models of lifetime customer value. Marketers will now need skills in designing 'value exchange' programmes to obtain the customer data. Marketers will need to become adept at multi-programme management to test rapidly and integrate multi-media, multi-channel programmes. Marketers will need to add integrative leadership to their traditional brand/product management skills.

Now they will focus on customer opportunities, which will become the driver of an evolving marketing organisation structure. The organisational focus will shift from brands to opportunities. Instead of new business ideas being generated within product management, we are 
Parsons

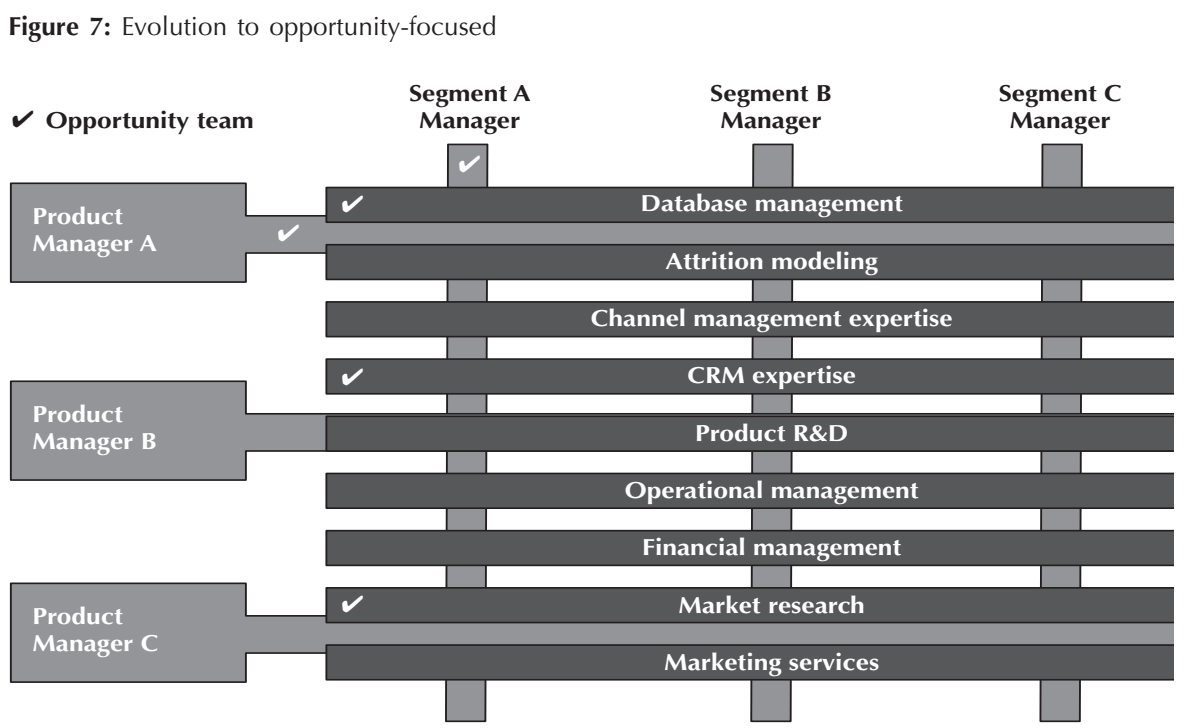

\section{We are starting to see forward- looking 'customer opportunity teams' which identify and realise new business concepts}

starting to see forward-looking cross-functional 'customer opportunity teams' which identify and realise new business concepts. These teams will blend segment/product and channel managers with functional specialists. This will displace the existing product-management-centric model that is better suited to big-bang marketing efforts. A customer opportunity team will mix ad hoc the set of skills required to capture a particular opportunity (Figure 7).

For example, in a financial services company the manager responsible for building the unsecured loans business may hypothesise that there is a major unexploited opportunity with small businesses. A team is set up including the small business segment manager, database systems, market research and CRM expertise to design an integrated product and communications programme for small businesses. Firstly, the team identifies and targets sales people against good potential loan prospects among current small business customers, while attracting desirable noncustomers by pre-approved credit offers. Then the team proactively increases credit lines based on anticipated customer needs while aggressively building deposit relationships. They become much more flexible about interest rates, proactively increasing or decreasing them based on customer behavioural analysis while developing information systems and decision processes that allow virtually immediate loan approval. In this example, a company following this type of approach increased lending to the small business segment by 30 fold in eight years, while profits went from zero to over $\$ 250 \mathrm{~m}$.

In these situations, staff requirements change. Marketing leadership becomes placing bets on a portfolio of opportunities and building an organisation with access to the diverse array of deep functional capabilities. To provide the leadership, marketers must stimulate a flexible and dynamic culture that can accommodate starting and indeed shutting down initiatives and opening up the organisation to new 


\section{New skills will be wasted without the systems infrastructure}

\section{If all this sounds like a lot to do, it is - and there isn't much time to get started on the journey}

technical skills and outside thinking. This differs sharply from the traditional inward-focused brand management model.

The organisational challenges of building the required capabilities are substantial. Even when the needs are identified and programmes developed, many senior executives say they cannot build the organisation fast enough to capture the opportunity. Typically they claim 'we lack the managers and skills and can't find the right people'. Often positions go unfilled for months because companies want to fill them internally rather than turning to external relationships. To balance their needs and those of the financial markets, companies will have to combine internal retraining, aggressive external hiring and external alliances for critical skills.

Of course, these skills will be wasted without the systems infrastructure. Companies will be upgrading their customer care systems, which integrate customer interface technologies with dynamically activated screens and scripts and allow customised and recallable dialogue with individual customers. Large data warehouses must be created with customer and transaction-level data, which provide a platform for behavioural-based segmentation. Data-mining software tools will analyse the large volumes of data to provide predictive modelling and comparisons of lifetime customer value. Campaign management software will help configure, execute and measure marketing campaigns. Finally, Internet applications software must be developed to customise content and advertising dynamically according to customer profile and online behaviour.

If all this sounds like a lot to do, it is - and there really isn't much time to get started on the journey, with new technology and competition potentially around every bend in the road.

Market research has identified four performance levels for interactive marketing (Figure 8). Most US companies are at Level 1, where they mass communicate similar value propositions to broad segments. Some have advanced to Level 2, with targeted communication of selected offers to narrow groups of customers, like American Airlines. A very few have reached Level 3, with behavioural segmentation (eg Fingerhut, Capital One), but none known of has reached Level 4, with a fully behavioural approach with multi-channel, event-driven interactions.

To move upwards on this ladder, companies will need to bolster their interactive marketing organisations and measure progress against key organisational parameters. For example:

- is interactive now regarded as a core element of the business?

- do you have teams with business-specific programme developers complemented by centralised functional departments and segmentspecific managers?

- are you deep in modelling and statistics with PhD-level staff?

- do you have instant access to customer data and analytic tools everywhere?

- is your business agenda driven by identifying customer opportunities?

Three companies that started on the journey have reached Level 2 and are moving towards Level 3. 
Parsons

Figure 8: Interactive marketing performance levels

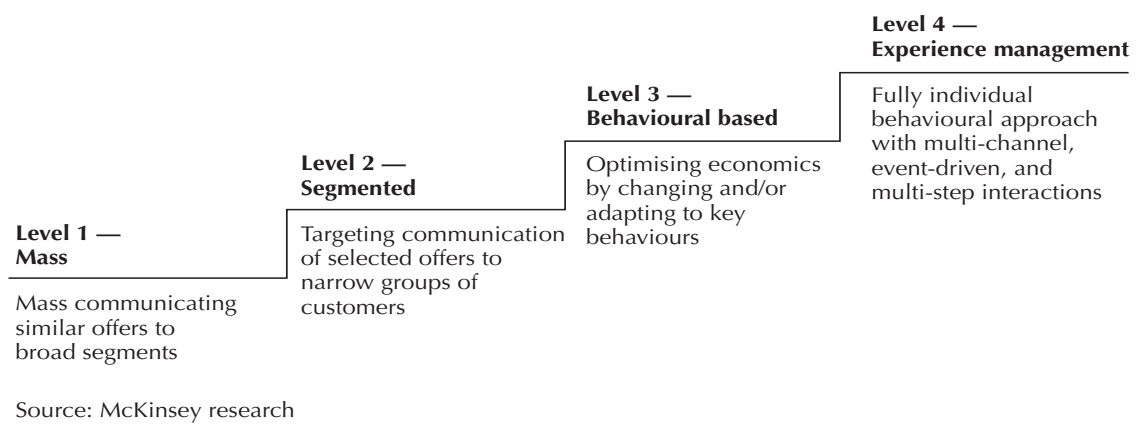

- A pharmaceuticals company invested $\$ 20 \mathrm{~m}$ to develop its first physician/prescriber database and then integrated sales and marketing functions to capture better data on prescriber activity and support more focused marketing efforts against target physicians.

- A major retailer acquired a leading direct marketer to provide a step change in its direct marketing and Internet capabilities and created a cross-channel customer database to allow more proactive tracking and development of customers.

- A home services provider developed customer lifetime value models to allow improved customer-specific product development and set up a customer test tab to iteratively test these new programmes. It also redesigned its senior management incentives to include segment performance objectives.

As firms assess how to build their interactive marketing capability, they will need to assess their position on five critical decisions:

- should they be a leader or follower?

- how much should they invest, and when?

- where should they start (which business, category or department)?

- should they keep their interactive capability separate or integrate it from the beginning with their traditional marketing organisation?

- and finally, which capabilities would it be better to access from the outside rather than building internally?

\section{Nothing fuels the growth of the interactive marketing culture like proven, quantified customer success stories}

Interactive marketing management teams that discuss and reach consensus around these questions will have taken a giant stride toward making interactive marketing a core element of their business, for some businesses the core element. The choice of where to start is particularly important because nothing fuels the growth of the interactive marketing culture like proven, quantified customer success stories. Just as new-age marketing needs to be dynamic, iterative and flexible, so a firm's organisational pilots should be selected so that wins proliferate and failures adapt to become wins.

Instead of trying to plan out every organisational detail, determine priorities and direction and just get started on the journey. One of the advantages of interactivity is that success will come from testing ideas and strategies, not from relying on experts' crystal balls. 